\title{
Environmental Sustainability, Energy Use and Economic Growth: An Analysis of Toyohashi City Energy-Economy Interaction
}

\author{
Nahid Hossain ${ }^{1}$, Yuzuru Miyata ${ }^{2}$ \\ ${ }^{1}$ (Graduate School of Engineering, Department of Environmental and Life Science Engineering, Toyohashi \\ University of Technology, Japan) \\ ${ }_{2}^{2}$ (Graduate School of Architecture and Civil EngineeringToyohashi University of Technology, Japan)
}

\begin{abstract}
Manufacturing and trading concentration, elevated economic activities and rise in urban population are the driving forces of city growths in the central part of Japan. Toyohashi city, locating between Tokyo and Nagoya, Osaka, is facing rapid growth for its industrial and port related economic concentration. As a result, use of natural resources and energy in the city is increasing. Recent trends show that to ensure economic growth, the City level energy use increased significantly. On the other hand, after the great disaster of 2011, Japan is concentrating more on natural resources to produce energy. The outcome would end in a higher use of natural resources like fossil fuels and natural gas. Finding an optimum solution to address energy-economy interactions is, therefore, becoming complex and difficult. Under the circumstances, this paper attempts to study the growth of Toyohashi city over time and resultant increase in consumption level of electricity and gas. Another objective of the paper is to find features of effect of technological yield in use of energy. The results of the study show that manufacturing and trading sector of the economy are causing expansionary pressure on use of combustion energy. The study also finds that contribution of technology to reduce use of energy in production side of the economy yet a dormant factor. Hence, introduction of technology to ensure improved and efficient use of energy has been recommended by the findings of the paper. The limitation of the study can be described as the limitation in research sample and data influence on the results coming out from market orientation. Difference in technology and direction toward the energy use was not taken care of by the study too.
\end{abstract}

Keywords: Economic growth of city, energy use, Environmental Kuznets Curve, Toyohashi city.

\section{Introduction:}

Faster urbanization and increasing economic activities in city areas are causing greater challenges to address better energy- technology -environmental management. Cities are emerging as the driving factor for economic activities and are supplying essential knowledge of production and innovation. The future cities are therefore a significant element of the global future. The typical structure, size and scope of city economic development are creating undesired impact on the protection of the natural resources. Therefore, understanding the relationship between city development and environmental collision is critical. Cities are the main user of world's energy. Since cities are vibrant and essential element of global development in terms of social, economic and technology, they need to offer their populations several services. Ensuring services need energy and, source of such energy is mainly based on fossil fuel. For example, Tokyo metropolitan area for her 12 million people consumes approximately 20Mtoe annually -which is equivalent to the total annual energy consumption of Bulgaria (IEE, Japan, 2008).

The relationship between energy consumption and economic growth has been described in several literatures. The general framework for determining the growth lies in the extended account of neoclassical approach represented by $D y=f\left(y, y^{*}\right)$, where Dy: growth rate of per capita output, $y$ : current level of per capita output, and $y^{*}$ : long run per capita output. The growth rate is diminishing for a possible output $y$ and rising in $y^{*}$ for given y. Economic growth $y^{*}$ depends on choices of environmental and economic variables of the economy (Hwang, 2008). Nevertheless the directions of causation of the relationship remain controversial when relationship between natural environment and economic growth is taken into account. Other studies suggest that different orders of causality exist between GDP and energy consumption. Kahn (2007) found pollution as emergent byproduct of three factors in a city: (1) scale, (2) composition, and (3) technology. He advocates that in developing the concept of "Green City", establishing local and global level benchmark for air, water quality, and greenhouse gas emissions are necessary. Sansoni, et al. (2010) decomposed transform in the environmental pollution by city growth into three effects: (1) demand composition shift effects, (2) output growth effects, (3) eco-efficiency change effects. They imply that the first effect can be positive or negative in the sense that the continued use of natural environment are increased or reduced. The second effect is negative, because more output means generally increased use of the natural environment. The third effect is positive, 
Environmental Sustainability, Energy Use and Economic Growth: an Analysis of Toyohashi City

owing to technological progress. Overall ability of Japan's energy conversion (usually measured as the amount of primary energy used to generate a unit of GDP) was high before the first oil price crisis of 1973-74. During the early 1970s it took as much as twice energy to produce a dollar of GDP both in the US and in Japan. But by 1990 the US required about 30\% less energy to produce a dollar of GDP than it did in 1974 and Japan had lowered the average energy to its economy by $35 \%$ (Zachariadis, 2007). Moreover, despite the appreciation of its currency, Japan was even more forward of the US in energy conservation than it had been before the first oil price crises of the early 1970s. After that an unexpected setback took place and between 1990 and 2005, the energy intensity of the US economy (inflation-adjusted) fell by $12 \%$, but the energy intensity of the Japanese economy first stood still and then, by the year 2000, was actually about $6 \%$ above the 1990 level. By the year 2005 it was about 3\% higher (Smil, 2007). Two factors can be recognized as the reasons for this reversal state: first, rising of demand for higher industrial energy and second, energy intensities of all major industries, after falling by $20-50 \%$ between 1973 and the late 1980s, had reached their lowest levels between 1988 and 1990, and had risen and became flat subsequently. By the year 2000, the energy intensity for the iron and steel industry, manufacturing, and ceramics were about 12\%, 15\%, and 17\% above the 1989 level respectively (Roney, 2011).

Environmental Kuznets Curve, EKC hypothesis provide empirical evidences that some pollutants follow an inverse-U-shaped pattern relative to income or growth of economy, as for many forms of pollution, environmental damage increases up to a certain level of GDP per capita, and then start decreasing as income increases further. Since the shape of EKC depends on the pollutant and income growth stage, different studies have found different shapes of the EKC (see Grossman and Krueger, 1991; Shukla and Parikh, 1992, Shafik and Bandyopadhyay, 1992; Beckerman, 1992; Stern, et al 1996; Stern and Common, 2001; and Dinda, 2004). The intensity of the argument in favor of different shaped EKC is crucial. The major argument is that, if the EKC hypothesis appears robust, then the perspective of an infinite accumulation of wealth is possible. Theoretically, the EKC relationship can be divided into three parts: scale, composition, and technology (Brock and Taylor, 2005). If an economy grows in scale, all activities including pollution increase proportionally. If growth is not proportional but accompanied by a change in the composition of goods and services produced, then pollution may decline or increase with income. Finally, if richer countries introduce less pollution-intensive production technologies, considering environmental quality a normal good, growth can lead to reduction in pollution. Of the empirical findings, inverse U-shaped by Shafik and Bandyopadhyay (1992), Panayotou (1993), Andreoni and Levinson (1998) provide evidences in the line of EKC hypothesis. On the contrary, findings of Vincent (1997), Grossman and Krueger (1993), Grossman and Krueger (1995) show an N-shaped EKC.

Most important concern of energy consumption is the resultant impact on the natural environment as well as finding proper remedy of such impact. This paper, therefore, attempts to find a relationship between economic growth of Toyohashi city and level of use of electricity and use by manufacturing and trading sectors if the economy. The structure of this paper is as follows: in section 2 energy consumption situation in cities of Japan has been described. The section also contains a brief description of study area or Toyohashi city. Objective and methodology of empirical testing model and explanation of major variables are illustrated in section 3. Econometric results of regression analysis and discussion are described in section 4. Concluding remarks and policy implication are drawn in section 5.

\section{State of Energy Use in Japan and Toyohashi City}

Japanese cities are experiencing rapid population growth causing graying of rural areas. Regional concentration of certain economic activities is contributing growth of certain regions. In the presence of shrinking population, declining 12.5 million by 2030 and 25 million by 2050, Japanese cities are growing in population. Data of Statistics Bureau, Japan, 2011, show that between 2005 and 2010 city population in Japan increased by $0.6 \%$ against national increase of by $0.2 \%$ leaving a decrease of $3 \%$ in the rural areas. Japanese success to achieve efficient use of industrial energy keeps the nation over any other developed country. Japanese manufacturers reduced energy consumption per unit of output by $40 \%$ between 1973 and 2003 (Agency for Natural Resources and Energy, 2005). France and Germany burn up nearly $50 \%$ t more energy than Japan to produce equivalent level of economic output. By the same scale, Britain's energy use is nearly double, the United States nearly triple, and China's almost eight times of Japan's level. Japan also ranks near the bottom among developed countries in $\mathrm{CO}_{2}$ emission per capita and GDP ratio. In the OECD, only Sweden has lower $\mathrm{CO}_{2}$ emissions to GDP ratio than Japan (Agency for Natural Resources and Energy, 2008). On the contrary, Japan's growing reliance on coal as a source for electricity production is threatening the situation. As of 2006, $\mathrm{CO}_{2}$ emissions (from fossil energy) were $111.8 \%$ of 1990 levels, $104.3 \%$ of 1995 levels, and $101.5 \%$ of 2000 levels. Final energy consumption in 2006 was $114.6 \%$ of 1990 levels, $103.4 \%$ of 1995 levels, and $100.1 \%$ of 2000 levels. Primary energy supply in 2006 was $115.6 \%$ of 1990 levels, $104.3 \%$ of 1995 levels, and $100.4 \%$ of 2000 levels (Sugiyama and Takeuchi, 2008). These statistics reflects that final energy consumption and/or primary energy supply in Japan were rising sharply in the 1990s and appeared to have more or less stabilized since 2000. However, in 2006 higher amount of final energy was consumed or primary energy was supplied 
Environmental Sustainability, Energy Use and Economic Growth: an Analysis of Toyohashi City

than that of 2000 levels. The larger part of such energy supply was met by coal power generation. On the other hand, after the great disaster of 2011, Japan is concentrating more on natural resources to produce energy. The outcome would end in a higher use of natural resources like fossil fuels and natural gas. Finding an optimum solution to address energy-economy interactions is, therefore, becoming complex and difficult.

Toyohashi city is located in the central part of Japan and falls in the prefectural boundary of Aichi. Area and population size of the city at founding in 1906 was at 19.69 square kilometers and 9,900 persons (Toyohashi City Statistics, 2011). At present the city size is 261.35 square kilometers with population of 381,977 (density stands at 1462 persons per square kilometer) (Toyohashi city web page, 2011). Attractive economic activity, especially concentration of heavy industries and a large scale sea-port, is attracting migration to the city and data of Statistics Bureau, Japan provide that 10,749 persons migrated to Toyohashi in 2008, 9,779 persons in 2009 , and 8,577 persons in 2010 . As a result, the city is experiencing vertical expansion as the land area is remaining unchanged since 1960 (Toyohashi city statistics, 2011). Fig. 1 show the trend of per capita manufacturing output in million yen and level of energy consumption of the city during the periods 1980-2009.
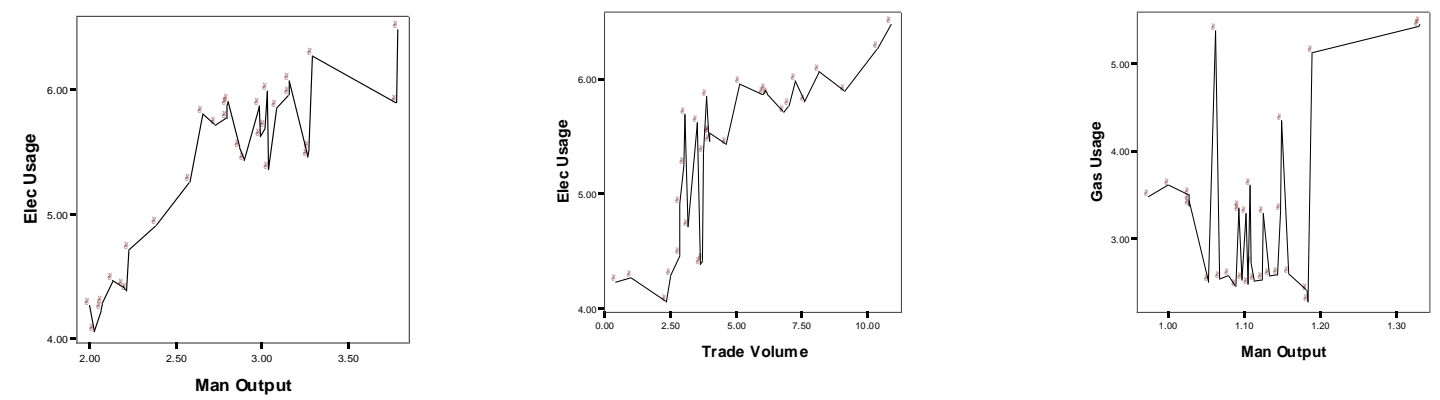

figure 1: Trend of per capita manufacturing output and trade volume in million yen and level of energy consumption of Toyohashi City during the periods 1980-2009.

Source: Compiled by authors from Toyohashi City Statistical Year Book, 2011

Fig. 1 implies that during the periods of 1980-2009, with the growth of Toyohashi city economic activities use of electricity and gas increased steadily. In October 1997, Toyohashi Port, Gamagouri Port and Tahara Port were united and constituted present Mikawa Port and it became a hub of international port and industrial activity. As a result, a rapid increase in the use of electricity has been found in trade sector. Advancement of technology and concern on environmental safety promoting efficient use of energy and as a technologically advance country Japan's success is noteworthy. Under the circumstances, it is expected that energy usage in Toyohashi city has been decreasing.

\section{Objective, Research Question, and Methodology of the Study:}

The purpose of this paper is to find out the relationship between technological contribution on the energy using sectors of an economy and consequent effect on the level of energy use. The broad objective of the paper is to find the links between urban economic growth or the scale of economy and environmental sustainability. The broad purpose of this paper thereby is to:

1. Outline city economy- energy use pattern,

2. Investigate technological contribution on efficient use of energy, and

3. Design potential plan for future energy use.

The present study aims to focus on following research questions:

1. Which production sector of the economy play pivotal role in using energy?

2. What is the effect on the use of energy when city economy grows?

3. How could Toyohashi city manage city growth and energy use dilemma?

Multiple regression models have been considered for the purpose of research. The relationship among the variables has been considered as linear. The basic idea of model formation comes from Grossman and Krueger's (1995). Consumption of energy has been considered as a function of manufacturing output, trade volume and population of Toyohashi city. The study pursues following hypotheses:

Hypothesis 1: With the growing concern of energy efficient production system, level of energy use in manufacturing and trading sector of a city in Japan is falling.

Since, better technological administration can open opportunities to make use of reduced level of energy, our study accounts following hypothesis:

Hypothesis 2: The energy efficient technology can shrink level of energy use while keeping growth of city economy. 
Multiple regression models have been considered for the purpose of research. The strength consumption relationship among the variables has been considered as linear. We consider following relationship between economy and level of energy use:

\section{EnergyUse $\equiv f$ (EconomicLevel: ManufacturingOutput,TradeVolume,Tech.Base)}

Using city level panel data, ordinary least square method is applied to estimate the implication of EKC for the city. Grossman and Krueger's (1995) econometric model has been formulated to quantify the EKC. The reduced form of OLS regression equation takes the form:

For level of electricity consumption: equations are,

$$
\begin{aligned}
& E_{i}=\alpha_{i}+\beta_{1} \ln M_{i}+\beta_{2} \ln M_{i}^{2}+\beta_{3} \ln M_{i}^{3}+ \\
& \beta_{4} \ln T_{i}+\beta_{5} \ln T_{i}^{2}+\beta_{6} \ln T_{i}^{3}+\varepsilon_{i} \\
& E_{i}=\alpha_{i}+\beta_{1} \ln M_{i}+\beta_{2} \ln M_{i}^{2}+\varepsilon_{i} \\
& E_{i}=\alpha_{i}+\delta_{1} \ln T_{i}+\delta_{2} \ln T_{i}^{2}+\varepsilon_{i}
\end{aligned}
$$

where E: level of electricity consumption, M: per capita manufacturing output of the city, T: per capita trade volume, $i$ represents $i$-th period and $\varepsilon$ is the error term.

For level of gas consumption: equations are,

$$
\begin{aligned}
& G_{i}=\alpha_{i}+\beta_{1} \ln M_{i}+\beta_{2} \ln M_{i}^{2}+\beta_{3} \ln M_{i}^{3}+\varepsilon_{i} \\
& G_{i}=\alpha_{i}+\beta_{1} \ln M_{i}+\beta_{2} \ln M_{i}^{2}+\varepsilon_{i}
\end{aligned}
$$

where G: volume of gas consumed in manufacturing, M: per capita manufacturing output of the city, $i$ represents $i$-th period and $\varepsilon$ is the error term.

The inverse-U shaped EKC is supposed to exist if $\beta_{1}$ has a positive sign and $\beta_{2}$ has a negative sign. The cubic part provides a more accurate measure of the relationship. If certainly a inverse U-shaped EKC exists, $\beta_{3}$ will have the similar negative sign as $\beta_{2}$ - meaning steady decrease in the pollution levels.

\section{Data description:}

Data used in this study try to analyze empirical evidence of EKC considering per capita manufacturing output, per capita trade volume, and volume of electricity and gas consumed for the specific purposes (manufacturing and trade) of Toyohashi city. The explanatory variables applied for the analysis are electricity consumed in $\mathrm{KWh}$, gas consumption in $\mathrm{M}^{3}$, manufacturing output and trade volume in million Yen. The data set covers the periods from 1980 to 2009 and the panel data of the study collects all the relevant data from Toyohashi city annual statistics. So in this study we have 30 year time period and we have 120 observations.

\section{Empirical results and discussion:}

The model OLS regression analysis results are provided in table 1. The regression coefficients estimated from the panel data are statistically significant, as indicated by the $t$-statistics. The results of table 1 show that level of electricity and gas use can be explained by the growth of manufacturing and trade volume. The effect of EKC hypothesis has been confirmed squared coefficient of $\ln \_M$ of equation (2). The squared coefficients of $\ln \_T_{-}$and $\ln \_M$ of equation (3) and (5) do not confirm EKC hypothesis. On the closer look, the cubic part of ln_M for level of electricity consumption has the similar sign of the squared part of the same variable. In contrary the cubic part of $1 n \_T$ for level of electricity consumption and $l n \_M$ for level of gas consumption have opposite signs of the squared part of the same variable.

Table 1: Regression results of the study equation 2,3 and 5.

\begin{tabular}{lll}
\hline & ln_E & ln_G \\
\hline Constant & -0.018 & 6.462 \\
\hline \multirow{2}{*}{ VAR1 } & $\begin{array}{l}2.871^{* * *} \\
(7.617)\end{array}$ & $\begin{array}{l}-10.483^{* * *} \\
(1.332)\end{array}$ \\
\hline \multirow{2}{*}{ VAR2 } & $\begin{array}{l}-1.206^{* *} \\
(6.353)\end{array}$ & $\begin{array}{l}7.071^{* *} \\
(1.767)\end{array}$ \\
\hline \multirow{2}{*}{ VAR3 } & $\begin{array}{l}-13.775 \\
(1.101)\end{array}$ & $\begin{array}{l}-23.376 \\
(0.96)\end{array}$ \\
\hline \multirow{2}{*}{ VAR4 } & $\begin{array}{l}-0.013^{* * * *} \\
(1.197)\end{array}$ & \\
\hline \multirow{2}{*}{ VAR5 } & $\begin{array}{l}0.034^{* * *} \\
(2.278)\end{array}$ & \\
\hline \multirow{2}{*}{ VAR6 } & -0.040 & \\
\hline$R^{2}$ & $(1.666)$ & \\
\hline
\end{tabular}


${ }^{* * *}$. Correlation is significant at the $1 \%$ (2-tailed)

** Correlation is significant at the $5 \%$ (2-tailed)

*. Correlation is significant at the $10 \%$ (2-tailed)

Numbers in the bracket denotes t-statistics

VAR1: $\ln \_$M, VAR2: $\ln \_M^{2}$,VAR3: $\ln \_M^{3}$,

VAR4: $\ln \_\mathrm{T}, \mathrm{VAR} 5: \ln \_\mathrm{T}^{2}$, VAR6: $\ln \_\mathrm{T}^{3}$

The results for economic level analysis are comparable to our priori expectations for growth of manufacturing sector and electricity consumption only. In case of growth trading sector and electricity use as well as growth of manufacturing sector and gas use priori expectation of the hypothesis does not correspond. While constituting EKC, the simulation results forms an inverse U-shaped EKC curve for electricity use only. The outcomes of simulation results are explained in fig. 2. The figures show the EKC for the periods of 1980 2009 for Toyohashi city. The foremost outcome is that the signs of $\beta_{5}$ and $\beta_{6}$ for ln_E and ln_T; $\beta 2$ and $\beta_{3}$ for ln_G and ln_M are opposite in nature.
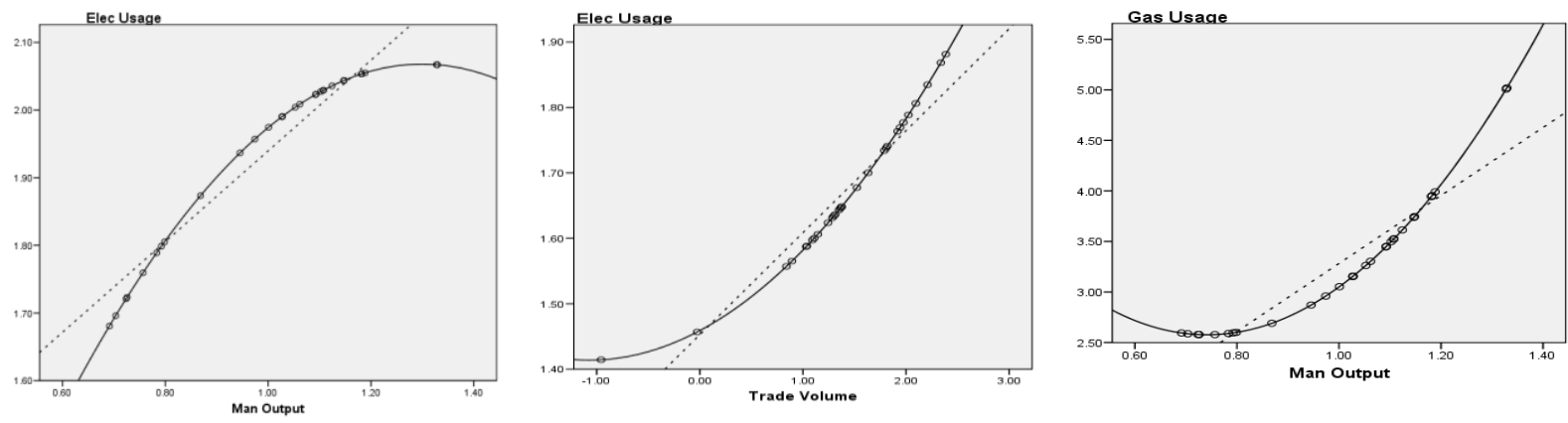

figure 2: Simulation results of correlation between economic activities and electricity and gas consumption of

Toyohashi City for the periods 1980-2009.

The study empirically examined the relation between city economic growth, technological competence and resultant effect on use of energy. As city grows, demand for electricity and gas as source of energy is expected to grow. Various sectors of the city contribute to allocate the demand. Our study found that during the period of 1980 to 2009, manufacturing output and trade volume of Toyohashi city grew steadily. As a result of such growth consumption of energy was increased too. Expansion in manufacturing and trade sectors contributed more on demand for electricity and gas. The squared coefficient between manufacturing and electricity use was positive, which means technological advancement could play significant role in decrease of electricity use while keeping growth of the sector. Significantly cubic part of the coefficient has the same sign of the squared coefficient, which means electricity use will continue to fall in manufacturing sector. On the other hand, squared coefficients between trading sector and electricity use as well as manufacturing sector and gas use are positive. The results demonstrate that technological efficiency in use of electricity and gas of the respective sectors fails to contribute efficiently. The findings are significant and have been demonstrated in fig. 2. The results provide theoretical and practical implication and proposition. As city grows, consumption of natural resources grows. The various sectors of the city contribute in different ways toward the situation and city energy planners need to highlight sector-wise usage of energy.

\section{Conclusion}

In the path of recovering and rebuilding from the disastrous earthquake and tsunami, Japan will have to decide whether to rely more heavily on inherently risky nuclear power and imported fossil fuels. Turning to renewable energy source instead of fossil fuels and nuclear power, would lead to healthier energy security, and economic well-being of its people (Roney, 2011). Our study suggests that even a city in Japan could play significant role in rearranging energy consumption level. Firstly, even the manufacturing and trading sectors of city grows, better innovation could contribute to improved energy input- output ratio. Since future direction of Japan's energy use remains fundamentally uncertain, our findings are suggestive. The inverse U-shape EKC of manufacturing output and electricity usage confirm that technological improvement is able to reduce use of energy usage and/or energy-output efficiency can be obtained by introducing better technology even economy continues to grow. The results follow the EKC hypothesis (Grossman and Krueger, 1995). On the other hand, EKC of trading and electricity usage and EKC of manufacturing and gas usage show an increasing trend. As a result, in future energy use in the said sectors tends to increase. The EKC interpretations of such outcome is significant in the sense that Japan need to address sector wise technological intervention to ensure efficient use of energy. Moreover, alternative source of energy production like solar, wind or bio-energy should be encouraged to reduce pressure on fossil fuels. The EKC of Toyohashi city demonstrates that idea of technological innovation could play a vital role in the management of efficient use of energy. The present EKC 
Environmental Sustainability, Energy Use and Economic Growth: an Analysis of Toyohashi City

can be viewed as the hypothesis on the interaction between economic growth, use of energy and environmental sustainability. However, the shape of the relationship is not uniform across sectors of the economy and differs in shape. The outcome is importance as public investment in energy consumption tie the process of improving environmental sustainability.

In spite of the implications, our study is not out of limitations. First, market orientation of the data would influence the results. The degree of correlation and influence differs according to the type of sector of the city. Second, sectors influencing energy consumption might have different technology and direction toward the state. This study did not count the difference in state of affairs. Thirdly, cross-city analysis was not done by the study. Analysis of other cities or neighboring cities is important to draw firm statistical benchmark. Lastly, this research did not cover the impact of technological improvement and competitiveness performance. Therefore, the effect of technology innovation and its competitiveness is left for future task. Comprehensive research outline considering wider factors and directions toward the research problems has also been kept for future scope.

\section{References:}

\section{Journal Papers:}

[1] Sansoni, M., Bonazzi, E., Goralczyk, M. and Stauvermann, P. J., RAMEA: How to Support Regional Policies towards Sustainable Development, Sustainable Development, 18, 2010, 201-210.

[2] Shukla, V., and Parikh, K., The Environmental Consequences of Urban Growth: Cross-national Perspectives on Economic Development, Air pollution and City size, Urban Georg , 13, 1992, pp. 422-449.

[3] Beckerman, W., Economic Growth and the Environment: Whose Growth? Whose Environment?, World Development, 20, 1992, pp. 481-496.

[4] Stern, D.I., Common, M.S., and Barbier, E.B., (1996). Economic Growth and Environmental Degradation: the environmental Kuznets Curve and Sustainable Development, World Development, 24 (2), 1996, pp.1151-1160.

[5] Stern, D.I., and Common, M.S., Is there an Environmental Kuznets Curve for Sulfur? Journal of Environmental Economics and Environmental Management, 41, 2005, pp.162-178.

[6] Dinda, S., (2004), Environmental Kuznets Curve Hypothesis: a Survey, Ecological Economics, 49 (2), 2004, pp. 431-455.

[7] Grossman, G.M., and Kreuger, A., Economic Growth and the Environment, Quarterly Journal of Economics, 110 (5), 1995 , pp. 353-377.

[8] Vincent, J., Testing for Environmental Kuznets Curves within a Developing Country, Environment and Developmental Economics, 2, 1997, pp. 417-433.

[9] Sugiyama, N., and Takeuchi, T., Local Policies for Climate Change in Japan; The Journal of Environment and Development, vol. 17 (4), 2008, pp.424-441.

[10] Kuznets, S., Economic Growth and Income Inequality, American Economic Review, 45 (1), 1955, pp.1-28.

\section{Books:}

[11] Ministry of the Environment, Material Flow in Japan 2006, (Government of Japan, Tokyo, Japan, 2009)

\section{Chapters in Books:}

[12] Brock, W. and Taylor, M. S., Economic Growth and the Environment: a Review of Theory and Empirics, in S. Durlauf and P. Aghion (ed.), the Handbook of Economic Growth, (Amsterdam, Holland, 2005).

\section{Proceeding Papers:}

[13] Hwang, E-G., A Close Look into Economic Growth Sources in Japan, South Korea and China, Working paper series, vol. 2008-21, the International Center for study of East Asian Development, Kitakyushu, Japan, 2008.

[14] Grossman, G.M., and Krueger, A.B., Environmental Impacts of a North American Free Trade Agreement, working paper no. 3914. National Bureau of Economic Research, Cambridge, MA, USA, 1991.

[15] Shafik, N., and Bandyopadhyay, S., Economic Growth and Environmental Quality: Time Series and Cross Country Evidence, Background paper for the world development report 1992. The World Bank, Washington, DC, 1992.

[16] Panayotou, T., Economic Growth and the Environment, Center for International Development at Harvard University Working Paper no. 56, Harvard, USA, 2001.

[17] Panayotou, T., Empirical Tests and Policy Analysis of Environmental Degradation at Different Stages of Economic Development, working paper no. WP238, Technology and Employment Program, International Labor Office, Geneva, Switzerland, 2003.

[18] Andreoni, J. and Levinson, A., the Simple Analytics of the Environmental Kuznets Curve, National Bureau of Economic Research Working Paper no. 6739, NEBR, 1998.

\section{Web Resources:}

[19] IEE, Japan, Japan Energy Brief, 2011, web resource: http://eneken.ieej.or.jp/en/jeb/1103.pdf, retrieved on May 28, $2012,2011$.

[20] Zachariadis, T., Exploring the Relationship between Energy Use and Economic Growth with Simple Models Evidence from Five OECD Countries; Economics Research Centre University of Cyprus, available at: http://ssrn.com//abstract=918754, 2007.

[21] Smil, V., Light behind the Fall: Japan's Electricity Consumption, the Environment, and Economic Growth, Japan Focus, Japan, April 2, 2007, retrieved on May 30, 2012.

[22] Kahn, J, Coking on Growth: Part III, in China, A Lake's Champion Imperils Himself, N.Y. Times, Oct. $14,2007$.

[23] Roney, M. J., Time to Rethink Japan's Energy Future, Earth Policy Institute, Web resource: www.earth-policy.org Retrieved on May 28, 2012.

[24] Agency for Natural Resources and Energy, Japan, web resource: http://www.enecho.meti.go.jp/english retrieved on April 6, 2012, 2008.

[25] Toyohashi City Web Page, 2011.; Web resource: http://www.city.toyohashi.aichi.jp/bu soumu/gyousei/toukei/index.htm, Retrieved on June 25, 2012.

[26] Toyohashi City Statistical Year Book, 2011. Web resource: http://www.city.toyohashi.aichi.jp/bu_soumu/gyousei/toukei/index.htm, Retrieved on June 11, 2012. 